\title{
Treatment of unprotected left main coronary artery stenosis with a drug eluting stent in a heart transplant patient with allograft vasculopathy
}

\author{
G Matos, L Steen, F Leya
}

Heart 2005;91:e11 (http://www.heartinl.com/cgi/content/full/91/2/e1 1). doi: 10.1136/hrt.2004.045096

High risk angioplasty with drug eluting stent placement into an unprotected left main coronary artery in a heart transplant recipient with allograft vasculopathy is reported. Ten month angiographic follow up is reported. The literature is reviewed and current methods of revascularisation are described in detail. This is the first report of drug eluting stent use in this clinical situation.

A llograft vasculopathy is the main cause of death in heart transplant recipients surviving the first year of transplantation. ${ }^{1}$ Medical treatment has very limited efficacy in preventing allograft vasculopathy. ${ }^{2}$ Coronary artery bypass grafting (CABG) is seldom possible because of the diffuse nature of the disease and is often a high risk procedure, carrying a $40-80 \%$ perioperative mortality. ${ }^{456}$ Retransplantation has worse prognosis than the first transplant procedure and is limited by a severe shortage of donor organs. Therefore, percutaneous coronary intervention (PCI) has been attempted and good immediate success and a varying rate of restenosis have been reported.

Unprotected left main coronary artery balloon angioplasty is technically feasible but procedural and three year mortality rates are high: $9 \%$ and $64 \%$ for elective cases, and $50 \%$ and $70 \%$ for acute myocardial infarction. ${ }^{7-9}$ Stenting improved procedural success rates $(>95 \%)$ in highly selected patients and improved restenosis in $14-23 \% .^{10}$ For elective stenting in patients with left ventricular ejection fraction $>40 \%$, $86 \%$ event-free survival was reported at six months. ${ }^{7}$

We report the first case of the treatment of unprotected left main coronary artery stenosis in a heart transplant recipient with drug eluting stent placement.

\section{CASE REPORT}

Significant allograft vasculopathy of the left main coronary artery was diagnosed in a 58 year old man. Subjective symptoms were worsening fatigue and decreasing exercise capacity. A dobutamine echocardiogram showed normal baseline systolic function and no wall motion abnormalities with stress. Coronary angiogram showed significant focal coronary artery disease in the proximal segments of the left anterior descending, circumflex, and right coronary arteries, as well as a shelf-like plaque in the proximal to mid-left main stem (fig 1A, B). The focal nature of obstructive lesions in the proximal coronary tree made angioplasty a technically feasible alternative. The patient had had three previous sternotomies for open heart surgery. Because of the high risk of CABG in this clinical presentation, the patient requested a staged series of angioplasties instead of another operation.

The patient's medical history was significant for orthotopic heart transplantation in 1989 for valvar cardiomyopathy, hypertension, and hypercholesterolaemia. The patient had had a single episode of documented grade lA, focal, mild, acute cellular rejection in 2001. Home medications were aspirin, clopidogrel, atenolol, pravastatin, amiodarone, prednisone, and cyclosporine. Complete blood count and a metabolic panel, including normal serial creatinine concentrations, were within normal limits. Low density lipoprotein ranged between $2.2-2.9 \mathrm{mmol} / \mathrm{l}$, high density lipoprotein between $0.7-0.96 \mathrm{mmol} / \mathrm{l}$, and triglyceride concentrations between $0.71-1.9 \mathrm{mmol} / \mathrm{l}$ over the preceding two years. He had previously undergone the following interventions: $2.5 \times 23 \mathrm{~mm}$ Cypher stent placement into the proximal right coronary artery and $2.5 \times 18 \mathrm{~mm}$ Cypher stent placement into the proximal circumflex coronary artery followed after
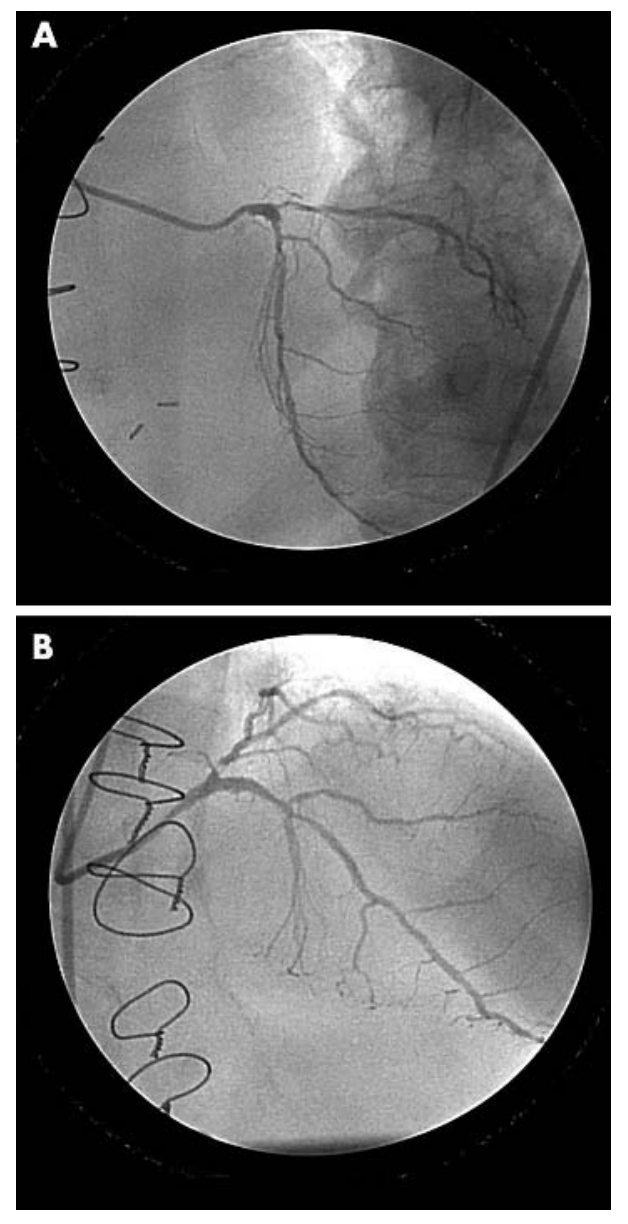

Figure 1 Angiographically significant focal proximal and mid lesions in the (A) left anterior descending and (B) circumflex coronary arteries. 

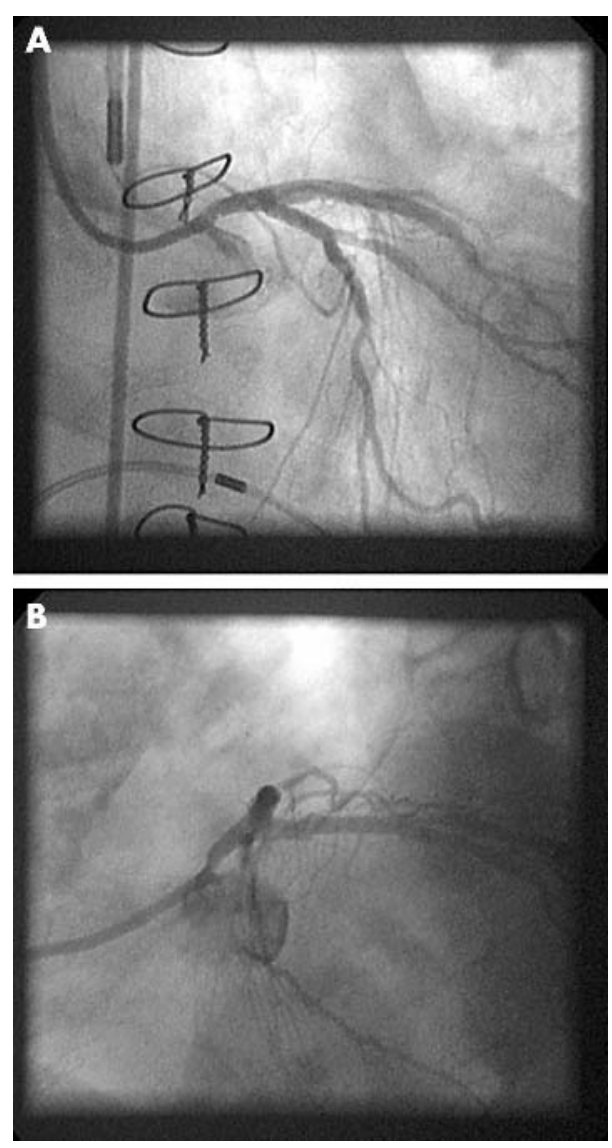

Figure 2 Left main coronary artery before angioplasty. (A) Anteroposterior (AP) projection demonstrates the shelf-like lesion on the proximal left main stem. (B) Left anterior oblique (LAO)-caudal projection showing the lesion in the proximal left main stem from a different angle.

several months with a $3 \times 28 \mathrm{~mm}$ Cypher stent placement into the proximal left anterior descending coronary artery.

The final, third phase of the above series of angioplasties was the intervention on the mid left main coronary artery stenosis (fig 2A, B). It was performed last so that this high risk procedure could be performed with an open vascular bed in the more distal segments. Also, the $3.5 \times 8 \mathrm{~mm}$ Cypher stent was not available in our institution at the time of the first two phases of the intervention. Intra-aortic balloon pump and temporary pacemaker were placed electively, and cardiovascular surgical back up was ascertained. Intravenous eptifibatide was started in the catheterisation laboratory and continued for 12 hours after the procedure. The left main coronary artery was intubated with a 6 French Judkins left guide catheter with side holes and the lesion was crossed with a 0.014 inch Sport coronary guidewire. The lesion was dilated with $2.5 \times 20 \mathrm{~mm}$ Raptor balloon at $6 \mathrm{~atm}$. It was positioned to cover the left main stem only, with the remainder of the balloon situated in the aorta to avoid the "watermelon seeding" phenomenon seen with shorter balloons. A $3.5 \times 8 \mathrm{~mm}$ Cypher stent was deployed in the left main stem at $14 \mathrm{~atm}$ with good results (fig 3A, B). Intravascular ultrasound showed appropriate sizing and good apposition of the stent to the vessel wall. There was no residual stenosis or evidence of complications. The intraaortic balloon and the pacemaker were removed, and both femoral arteries were closed with closing device. The patient left the hospital the following day. On the basis of randomised studies, ${ }^{11}{ }^{12}$ one year treatment with clopidogrel was recommended. On clinical follow up at six weeks after
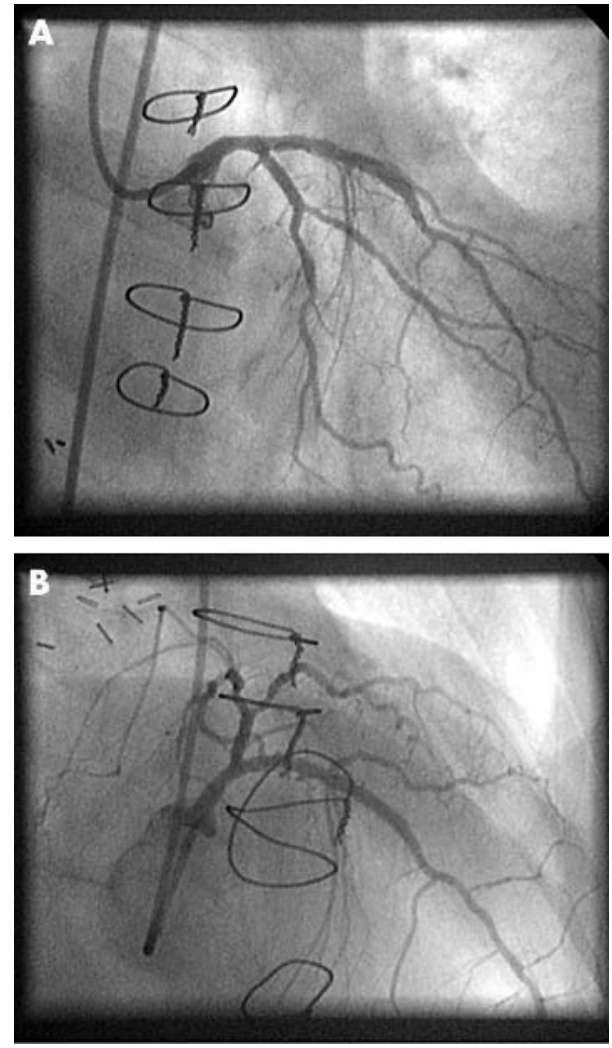

Figure 3 Left main coronary artery after stent deployment. (A) AP projection shows the disappearance of the shelf-like lesion after stenting. (B) LAO-caudal projection showing the widely opened left main after angioplasty.

the angioplasty, the patient commented on improvements in his ability to perform sustained exercise. Five and 10 months after the procedure, the patient had elective follow up angiograms. They showed patent stents in the left main, right, and circumflex coronary arteries. There was minimal angiographic restenosis in the left anterior descending artery stent.

\section{DISCUSSION}

Allograft vasculopathy is the leading cause of death and morbidity after the first year of transplantation. Its prevalence is high: $11 \%, 22 \%$, and $45 \%$ at one, two, and four years after transplantation, respectively..$^{13}$ The accelerated coronary artery disease involves both the epicardial and the intramyocardial arteries. Its diagnosis is difficult because of the absence of angina in the denervated heart and the low sensitivity of non-invasive stress testing. ${ }^{15}$ The first manifestation of allograft vasculopathy is often congestive heart failure, ventricular arrhythmias, or sudden death. ${ }^{16}$ The ineffective medical treatment and the limited suitability of CABG and retransplantation have motivated interest in PCI for the subset of heart transplant recipients presenting with allograft vasculopathy in proximal segments. Schnetzler and colleagues ${ }^{17}$ reported $94.3 \%$ primary success $(<50 \%$ residual stenosis) in 53 lesions. Two of these patients had symptomatic left main stenosis, which were dilated with success. One patient, however, had restenosis and later underwent CABG with success. There was no periprocedural mortality and the six month restenosis rate (defined as percentage stenosis $>50 \%$ ) was $32.5 \%$. Musci and colleagues ${ }^{5}$ described 46 of 124 patients who underwent 76 PCIs for allograft vasculopathy. The primary success rate was $96 \%$ and the angiographic restenosis was $42 \%$ at 11 months. There was no 
procedure related death. Halle and colleagues ${ }^{6}$ reported 55\% (42 of 76 lesions) restenosis at a mean (SD) of 8 (5) months. Redonnet and associates ${ }^{18}$ reported $67 \%$ restenosis after balloon angioplasty and 64\% restenosis with stenting in 37 lesions of nine patients. The reported restenosis rates are variable because of the use of different definitions of restenosis, variable intervals between the procedure and follow up angiography, and the use of stents and adjunctive debulking techniques. Nevertheless, the rate of restenosis seems to be significantly higher in transplant recipients than in non-transplant recipients enrolled in restenosis prevention trials.

CABG remains the preferred treatment for left main disease. However, the introduction of stenting, which reduces both the immediate complications of balloon angioplasty and the long term restenosis rate, has prompted the use of left main stenting in patients with contraindications to surgery with promising initial results. ${ }^{79-21}$ De Gevigney and colleagues $^{22}$ reported the outcome of left main stenting with bare metal stent in two heart transplant recipients. Initial angiographic results were excellent in both cases. At five month follow up angiography, both patients had high grade in-stent restenosis, which was treated with CABG. One of the patients died during surgery. Repeated sternotomies carry a high risk for complications caused by mediastinal scarring from the previous heart surgery and an often difficult postoperative course of the already chronically immunosuppressed patients. The introduction of drug eluting stents may improve the restenosis rate and provide a less invasive, safer option for revascularisation for heart transplant recipients. To optimise the technical success of stenting in this paramount location, we recommend the use of intravascular ultrasound to better determine the size of the vessel and the extent and exact location of the lesion and to ascertain the completeness of deployment and apposition of the stent.

The management of allograft vasculopathy is a difficult clinical problem that requires close collaboration between the medical and surgical teams. Patients with left main stenosis present a particularly difficult challenge. Stent implantation is technically feasible and is associated with a predictable and optimal initial result. The problem relates to the unknown risk of restenosis in these patients with often fatal clinical presentation. Routine follow up angiography appears to be necessary for the timely diagnosis of restenosis. Intracoronary brachytherapy was shown to be feasible for the treatment of in-stent restenosis in a small cohort of transplant patients. ${ }^{23}$ The effect of drug eluting stents on left main restenosis in heart transplant recipients needs further investigation, as this treatment modality may be an effective alternative for this very high risk group of patients.

\section{Authors' affiliations \\ G F Matos, L Steen, F Leya, Department of Cardiology, Loyola University Medical Center, Maywood, Illinois, USA}

The authors have no competing interest, and they have nothing to disclose. Written informed consent was obtained from the patient. The manuscript strictly adheres to the ethics committee guidelines.
Correspondence to: Dr Gabor F Matos, Department of Cardiology, Loyola University Medical Center, 2130 South First Avenue, Maywood, IL 60153, USA; gmatos@lumc.edu

Accepted 11 October 2004

\section{REFERENCES}

1 Hosenpud JD, Novick RJ, Bennett LE, et al. The Registry of the International Society for Heart and Lung Transplantation: thirteenth official report-1996. $J$ Heart Lung Transplant 1996;15:655-74.

2 Hoyt G, Gollin G, Billingham $M$, et al. Effects of anti-platelet regimens in combination with cyclosporine on heart allograft vessel disease. J Heart Transplant 1984;4:54-6.

3 Billingham ME. Cardiac transplant atherosclerosis. Transplant Proc 1987;4:9-25

4 Copeland JG, Butman SM, Sethi GK, et al. Successful coronary artery bypass grafting for high risk left main coronary artery atherosclerosis after cardiac transplantation. Ann Thorac Surg 1990;49:978-83.

5 Musci M, Loebe $M$, Wellnhofer $E$, et al. Coronary angioplasty, bypass surgery, and retransplantation in cardiac transplant patients with graft coronary disease. Thorac Cardiovasc Surg 1998;46:268-74.

6 Halle AA, DiSciascio G, Massin EK, et al. Coronary angioplasty, atherectomy and bypass surgery in cardiac transplant recipients. J Am Cardiol 1995;26:120-8.

7 Ellis SG, Tamai $\mathrm{H}$, Nobuyoshi $M$, et al. Contemporary percutaneous treatment of unprotected left main coronary stenoses: initial results from a multicenter registry analysis 1994-1996. Circulation 1997;96:3867-72.

8 Marso SP, Steg G, Plokker T, et al. Catheter-based reperfusion of unprotected left main stenosis during acute myocardial infarction (the ULTIMA experience). Am J Cardiol 1999;83:1512-6.

9 Kosuga K, Tamai H, Ueda K, et al. Initial and long term results of angioplasty in unprotected left main coronary artery disease. Am J Cardiol 1999:83:32-7.

10 Wong P, Lau KW, Lim YL, et al. Stent placement for non-STRESS/BENESTENT lesions: a critical review. Cathet Cardiovasc Interv 2000;51:223-33.

11 Mehta S, Yusuf S, Peters R, et al. Effects of pretreatment with clopidogrel and aspirin followed by long-term therapy in patients undergoing percutaneous coronary intervention: the PCI-CURE study. Lancet 2001;358:527-33.

12 Steinhubl SR, Berger PB, Mann JT 3rd, et al. REDO Investigators Clopidogrel for the reduction of events during observation. Early and sustained dual oral antiplatelet therapy following percutaneous coronary intervention: a randomized controlled trial. JAMA 2002;288:2411-20. Erratum in 2003;289:987

13 Yeung AC, Davis SF, Hauptmann PJ, et al. Incidence and progression of transplant coronary artery disease over 1 year. J Heart Transplant 1995; 14:S215-20.

14 Constanzo MR, Naftel DC, Pritzker MR, et al. Heart transplant coronary disease detected by angiography: a multi-institutional study. J Heart Lung Transplant 1996;15:S39

15 Smart FW, Ballantyne CM, Cocanougher B, et al. Insensitivity of noninvasive tests to detect coronary artery vasculopathy after heart transplantation. Am J Cardiol 1991;67:243-7.

16 Gao SZ, Schroeder JS, Hunt SA, et al. Acute myocardial infarction in cardiac transplant recipients. Am J Cardiol 1989;64:1093-7.

17 Schnetzler B, Drobinski G, Dorent R, et al. The role of percutaneous coronary angioplasty in heart transplant recipients. J Heart Lung Transplant 2000;19:557-65.

18 Redonnet M, Tron C, Koning F, et al. Coronary angioplasty and stenting in cardiac allograft vasculopathy following heart transplantation. Transplant Proc 2000;32:463-5.

19 Wong P, Wong CM, Ko P, et al. Elective stenting of unprotected left main coronary disease. Cathet Cardiovasc Diagn 1996;39:347-54.

20 Weston MW, Spoto E Jr, Aranda J, et al. Endovascular stenting of an unprotected left main coronary stenosis in a heart transplant patient. Clin Cardiol 1998;21:919-22.

21 Kong W, Le May MR, Labinaz M, et al. Stenting of an unprotected left main coronary stenosis in a cardiac transplant patient. Can J Cardiol 1999;15:1131-5

22 De Gevigney G, Roriz R, MacFadden E, et al. Should we still perform angioplasty and stenting of an unprotected left main coronary artery stenosis in heart transplant patients? Two new cases and a review of the literature. $J$ Heart Lung Transplant 2001;20:1217-9.

23 Grise MA, Reilly JP, Tobis JM, et al. Intracoronary radiation to treat in-stent restenosis in six cardiac transplant patients. Cathet Cardiovasc Interv 2003;60:41-4. 